\title{
Inventando a Hayden White. Imaginación y narrativas, Norma Durán (coord.)
}

\author{
Matteo Arias Díaz
}

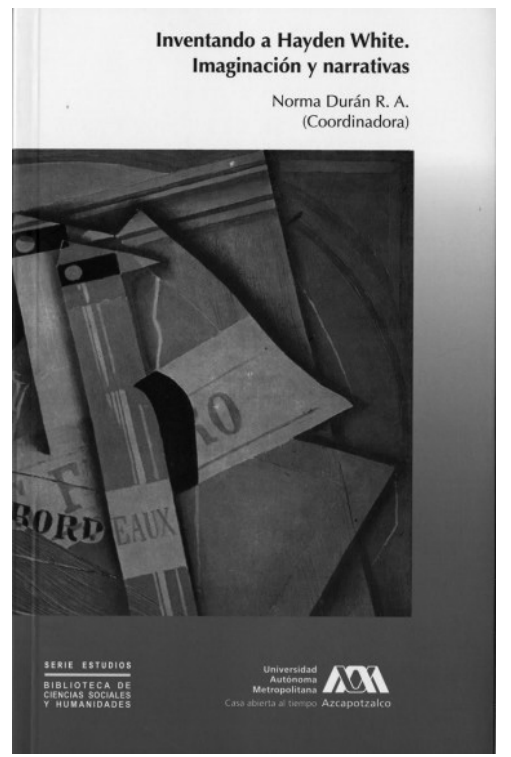

Durán, Norma, coord. Inventando a Hayden White. Imaginación y narrativas. México: UAM, 2020.
La gente dice que hago colapsar o que disuelvo la distinción entre hecho y ficción, entre literatura e historia: lo hago con el fin de mostrar lo que tienen en común como productos de enunciados performativos que son de naturaleza retórica, y cuyo efecto es el de la construcción ideológica de la realidad. Hayden White ${ }^{1}$

Una constante a lo largo de la vida del historiador Hayden White fue que recibió numerosas críticas por parte de sus detractores. ${ }^{2}$ Inmediatamente después de la publicación de su polémica

\footnotetext{
Alfonso Mendiola, "Hayden White: la lógica figurativa en el discurso histórico moderno", Historia y Grafía 12 (1999), 229.

2 Lo tildaron de negacionista, relativista, determinista verbal, escéptico y hasta de filósofo de la historia, pero no de historiador.
} 
Metahistoria en 1973, muchos tomaron la pluma para cuestionar al autor norteamericano. En respuesta, White dedicó gran parte de su producción escrita a continuas reflexiones y, sobre todo, respuestas, más que nada en forma de ensayo, ${ }^{3}$ para reformular su postura o contraargumentar. Esto lo llevó a engendrar más de una forma de pensamiento respecto a la tesis contenida en aquel libro de 1973. El historiador estadounidense fue, de manera gradual, transitando entre autores y corrientes filosóficas-literarias con el fin de alcanzar aquello que tanto había buscado: ${ }^{4}$ una postura delineada acorde al llamado de una renovación en la teoría de la historia, ya que arrastraba viejos estatutos decimonónicos obsesionados con la cientificidad.

Esta reseña va a desarrollarse en cuatro ejes, cada uno con un mote propio: los dos primeros, centrados en temas de historia y literatura; los otros dos, en la relación entre historia y narrativa. Cada una de estas dos partes está subdividida según algunas diferencias halladas en los artículos, ocho en total, que comprende el libro. Antes de entrar de lleno, quisiera comenzar con algunas puntualizaciones que la coordinadora del texto, Norma Durán, establece en la introducción.

En primer lugar, Durán nos exhorta a continuar la reflexión dentro de la práctica de los historiadores, sin perder de vista la lectura de Hayden White. Quedan muchos retos al momento de emparentar la historia con la literatura ${ }^{5}$ (como resultado de un acto poético ${ }^{6}$ al interior del discurso historiográfico), aun cuando se acepta que "la historia construye el pasado histórico"? Este último punto es central: para White

3 Ver Hayden White, "Respuesta a las cuatro preguntas del profesor Chartier”, Historia y Grafia 4 (1995): 317-329. "Su obra es, antes que nada, un diálogo sostenido a lo largo de toda su vida [...] En cada nuevo ensayo la explicación que hace de ella [de su obra] va cambiando”. Norma Durán (coord.), Inventando a Hayden White. Imaginación y narrativas (México: UAM, 2020), 176.

4 "Del primer al último White hay matices, reconfiguraciones, aclaraciones, correcciones, y mucha reflexividad”. Durán, Inventando a Hayden White, 11.

5 Ver Ivan Jablonka, La historia es una literatura contemporánea. Manifiesto por las ciencias sociales (Buenos Aires: FCE, 2016).

${ }_{6}$ Del griego $\pi$ oté $\omega$ (poieo), crear.

7 Durán, Inventando a Hayden White, 13. 
resultaba ineludible la naturaleza poética e histórica de las formas narrativas implícitas en la historiografía. En segundo término, nos sumergimos en un acto reflexivo, pues, como el título lo indica, pensar la obra de Hayden White en la segunda década del siglo Xxi es, inevitablemente, una invención, una apropiación. En tercer lugar, pasamos por una necesaria contextualización del panorama intelectual: ${ }^{8}$ los años ochenta del siglo xx se erigen como una época en la cual la historia, como disciplina, se tambalea. La crisis del paradigma histórico planteó un jaque con el advenimiento de corrientes que proponían una nueva óptica al momento de producir y leer narrativas del pasado. ' Tener esto en mente es fundamental para comprender el origen del pensamiento whiteano. No es, ni de lejos, una digresión innecesaria.
Conforme uno va leyendo el libro, va desvelando un compendio de textos llenos de múltiples texturas, aristas. Cuando uno se adentra en sus páginas, puede percibir diversas capas "sobre lo que parece ser lo mismo, pero que bajo otra mirada resulta ligera y radicalmente, distinto". ${ }^{10}$ Ahora sí, entremos de lleno con los cuatro ejes referidos.

El primero (de la rebeldía) comprende única y exclusivamente la observación de José Rabasa sobre lo que él denomina "el último White", nomenclatura que incluye un juego de palabras muy particular. Por un lado, Rabasa hacer referencia a la última versión del pensamiento whiteano expresado en The practical past (2014) y, por otro, al fin del "historiador blanco" con un sesgo objetivista, centrista y obsoleto. ${ }^{11}$ El Hayden White que lee

8 "La pregunta que nos queríamos plantear es la siguiente: qué del pensamiento whiteano sigue vivo y qué no. Preguntarse por la vigencia de una obra nunca será negarla, sino aceptar que se escribió en un contexto y que ese contexto cambió”. Durán, Inventando a Hayden White, 13.

9 Como el giro lingüístico y el giro historiográfico. Hay que recordar que Metahistoria nació inscrito en la lógica del estructuralismo, el cual priorizaba la estructura del lenguaje, desde la escritura, como forma de análisis de los textos. Es decir, estudiaba los significados de los textos literarios (discursos) desde los componentes lingüísticos, gramaticales y retóricos. Durán, Inventando a Hayden White, 23-27.

10 Durán, Inventando a Hayden White, 63.

11 "Tal perspectiva de la ciencia era consistente con las filosofías dominantes del positivismo y el utilitarismo que contribuyeron a la transformación de la visión del mundo científico en un Wel- 
Rabasa rechaza las pretensiones científicas de la historia y defiende la presencia de la ficción, entendida como producción de sentido, en la labor del historiador. Romper con la herencia decimonónica desde una nueva filosofía de la historia es acabar con ese último historiador blanco. Por ello, la enunciación adquiere aquí un carácter en extremo relevante debido a que no es la exposición de hechos, sino las formas de pensar el pasado, de escribirlo... Cuando White se acerca a la entidad histórica Holocausto, prefiere las novelas posmodernas de W.G. Sebald, Primo Levi y otros, pues, para él, revelan mucho más desde su carácter literario que cualquier otro texto histórico tradicional. ${ }^{12}$ White buscaba entender cómo estas obras literarias hacen sentir, nunca asir, ${ }^{13}$ ese todo que representa el acontecimiento. Por consiguiente, siguiendo con la línea de la reflexividad, Rabasa observa las observaciones, lee las lecturas, que White generó acerca de estas novelas.

Dentro de nuestro segundo eje (de las expectativas), encontramos a Silvia Pappe y Carlos Mendiola. Pappe, igual que Rabasa, estudia la forma en que White leyó Austerlitz de W.G. Sebald, sólo que en este caso se vuelve mucho más explícita la reflexividad, así como la noción de pasado práctico (resultado de una praxis; un acto performativo). ${ }^{14}$ Esto es, profundiza en cómo el pasado es resultado de determinadas expectativas-experiencias, una ética y una poética. ${ }^{15}$ A su vez, se trata de ver las formas más que los contenidos:

tanschauung, que le permitió a la 'historia' en general ser considerada como una prueba irreprochable del progreso de la civilización y el triunfo de las entonces razas blancas del mundo”. Durán, Inventando a Hayden White, 33. Esto es, el White de Rabasa rechaza tajantemente la pedantería y arrogancia occidental al adjudicarse exclusividades, superioridades en la historia profesionalizada, tras el escudo de la neutralidad y el empirismo.

12 El lenguaje figurativo otorga mucha mayor fuerza al discurso. Todo esto con el objetivo de demostrar que lo literario no se opone a la historia, sino que hay una fuerte interrelación.

13 Aun la más poderosa pluma no podría captar la verdad completa, real, esencial”. Durán, Inventando a Hayden White, 48

14 El acto performativo es aquel que no busca transmitir hechos (verdad/falsedad), sino conseguir un resultado (éxito/fracaso en el convencimiento por medio del proceso comunicativo).

15 Durán, Inventando a Hayden White, 67. Sin perder de vista el carácter literario de la historiografía. 
"si algo hemos aprendido de Hayden te con Alfonso Mendiola y Norma White es que las formas de leer influyen Durán. Tozzi centra su atención en en la escritura". ${ }^{16}$ De igual manera, la artefactualidad, la forma en que la Carlos Mendiola, desde su lectura de relación presente productor-pasado Ánima, ${ }^{17}$ ahonda en cómo la perspecproducido se manifiesta tropológicativa y la experiencia del tiempo, otra mente en la escritura de la historia. vez la fragancia de Koselleck, invaden El White de Tozzi entiende la grafía las páginas, influyen en la asignación histórica como una de naturaleza perde sentidos a la realidad: "darle sentido formativa, que crea realidades. Esta al organismo propone el fin (telos) que podría tener". ${ }^{18}$ Sigue con su análisis de la capacidad de juzgar reflexionante para la comprensión del mundo, es decir, del estudio del juicio teleológico kantiano, y cómo éste influye en la idea de artefacto literario en White, siempre desde la posición del telos. ${ }^{19}$

Verónica Tozzi introduce el tercer eje (del realismo figural) que comparúltima palabra, realidad, es el concepto clave para desentrańar este artículo, ya que la discusión gira en torno a los diferentes tipos de realismo. ${ }^{20} \mathrm{Al}$ leer Mimesis de Erich Auerbach, a través de White, Tozzi llega a la noción de "causalidad figural" y concluye de que el pasado "no es un objeto de contemplación, ni una idea en la mente, sino esa situación real de desajuste, desafío

16 Durán, Inventando a Hayden White, 68. Las cursivas son mías. Pappe analiza cómo repercutió, consciente o inconscientemente, la mediación de la novela histórica posmoderna en el White que ella inventa; no le importa Austerlitz per se.

17 Ver Wajdi Mouawad, Ánima, traducción de Pablo Martín (Barcelona: Destino, 2014).

18 Durán, Inventando a Hayden White, 103.

19 "Hayden White sostiene que el medio que mantiene unido el campo literario es el lenguaje y que su fin es poner a prueba dicho instrumento de mediación”. Durán, Inventando a Hayden White, 109.

20 Durán, Inventando a Hayden White, 119-123. Al contrastar el discurso representacionalista de Arthur C. Danto (realismo representacionalista) con el pragmatismo de George H. Mead (realismo perspectivista). "La historia produce un efecto de realidad porque sigue la forma del relato inventado por la literatura realista (Balzac, Flaubert, Zola)”. Durán, Inventando a Hayden White, 163. Paradójicamente, desde el siglo XIx (con el realismo literario), historia y literatura están ligadas de forma íntima, sin embargo, la primera ha buscado renegar de la segunda. White, historiador rebelde, pretendió por mucho tiempo derrumbar esas fronteras. 
en el presente que nos obliga a refigurar, reorganizarnos, reajustarnos para seguir actuando". ${ }^{21}$ Este White diagnostica reformulaciones continuas de los ejercicios interpretativos que termina por ser la historia: el pasado (que sí es/existe en este White; no niega su facticidad) emerge de diferentes formas en los presentes que operan de manera estética-performativa mediante la historiografía. ${ }^{22}$

No obstante, Alfonso Mendiola inventa un Hayden White con otros matices, a pesar de que también ausculta la apropiación de Auerbach por parte del historiador norteamericano. Continúa el cuestionamiento por el realismo figural auerbachiano-whiteano en el discurso histórico, pero él radicaliza la postura, al exaltar la poética de la historia aplicando los tropos (como elementos artísticos) y los recursos ficcionales dentro de la representación histórica. En otras palabras, Mendiola focaliza su atención en la sustancia narrativa, pues "la historia no existe independientemente de su narración", ${ }^{23}$ así concede una inevitable mediación comunicativa al interior de la historia. No hablamos de hechos sino de comunicaciones. ${ }^{24}$ Lo anterior significa que, como tal, no tenemos acceso al pasado, sino sólo a artefactos literarios, mediaciones comunicativas que conforman dichos pasados. ${ }^{25}$ Esta postura rechaza la ontología del pasado, el pasado-cosa, para hacer hincapié en la relación historia-literatura. Por lo cual, White no considera posible la “investigación empírica del pasado". ${ }^{26}$

21 Durán, Inventando a Hayden White, 143.

22 "Y también hay 'realidad', los hechos del pasado, las figuras pasadas, son reales pero reales en el presente en el que se consuman y la consumación refigura el pasado”. Durán, Inventando a Hayden White, 151.

23 Durán, Inventando a Hayden White, 173. Ver Alfonso Mendiola, Retórica, comunicación y realidad (México: UiA, 2003).

24 Durán, Inventando a Hayden White, 173. "Esto es, no existe el Renacimiento fuera de los libros que nos hablan de él”.

25 “¿En qué sentido nos da el texto acceso al pasado? Sí puede, sólo si encuentras tu camino; tienes que buscar tu camino a través del texto. Por lo demás, el pasado que se presenta está ya procesado ideológicamente”. Durán, Inventando a Hayden White, 228.

26 Durán, Inventando a Hayden White, 237. 
En cuanto a Durán, leemos cómo la retórica vuelve, como neorretórica, en la década de los sesenta del siglo $\mathrm{xx}$, gracias a que se introdujo la posibilidad de pensar en las formas de escribir. Esta idea parece obvia en la actualidad, pero para el siglo xIX y la primera mitad del xx no lo era. El White de Durán (influido por Giambattista Vico, Erich Auerbach, los estructuralistas, Immanuel Kant) es aquel enfocado en observar la enunciación y no el enunciado; ${ }^{27}$ que mira con detenimiento el uso del lenguaje más que lo que se dice como tal. De esta manera, se hace patente la historicidad de la propia historia: hay diferentes articulaciones/significaciones del pasado histórico. Tanto Mendiola como Durán concuerdan en que el pasado existe en la forma narrativa-literaria (trama) que lo engendra de manera lingüística. Aunque, “esto no significó que White negara la existencia del pasado, pues lo que siempre defendió es que los acontecimientos existían, pero que los hechos que son descripciones de los acontecimientos y que están inscritos en una trama sólo son perceptibles en el discurso histórico" ${ }^{28}$

Finalmente, el cuarto eje (de los contextos) lo componen Ricardo Nava y Fernando Betancourt. Respecto al primero, retomando el artefacto literario, Nava conjunta la aproximación whiteana con la de Jacques Derrida, ${ }^{29}$ con miras a fortalecer la discusión en el terreno de la escritura, visible durante la segunda mitad del siglo xx. También repasa las distintas maneras de leer textos (hermenéutica y semiología) según contextos, ${ }^{30}$ donde cada escrito, por ende, será leído siempre

27 Ver Norma Durán, "La transformación en las formas de lectura: del formalismo al contextualismo", en Formas de hacer la historia. Historiografía grecolatina y medieval (México: Ediciones Navarra, 2001), 24-39.

28 Durán, Inventando a Hayden White, 200. Esto denota la influencia de Vico en White.

29 Ver Ricardo Nava, "Historia, escritura y acontecimiento", Historia y Grafía 46 (2016), 15-52. La escritura emerge, en consecuencia, como una impresión que sobrevive al contexto y al autor que le dio vida, sólo para quedar sujeta a un nuevo escritor: el lector. El proceso comunicativo nunca está en el emisor, sino en el receptor (lector) que lo interpreta. Lo mismo ocurre con cualquier tipo de grafía: al momento de visualizar un escrito, importa el sentido asignado por el observador .

30 Durán, Inventando a Hayden White, 211. “[...] poniendo el acento no en la pregunta por el sentido de algo sino por cómo eran leídas en distintos contextos y a partir de qué prácticas de lectura”. 
de forma singular: la lectura pura de un texto es imposible. Nunca conocemos el sentido originario (a manera de valor absoluto) de un texto, ni siquiera el autor mismo. Cada lectura es una sobreescritura de un libro. Siguiendo este hilo, no hay un solo White: hay muchos, en tanto que los lectores se acerquen a sus textos y los reapalabren desde su lugar de enunciación. Toda lectura es una práctica histórica y, por tanto, cambiante e interminable.

Por último, Fernando Betancourt cierra con "el ejercicio autorreflexivo como componente central de la propia operación historiográfica”. ${ }^{31}$ De modo que, el contexto, pero sobre todo, el papel del observador, más que lo observado, adquieren una gran relevancia dentro de las estructuras narrativas que conforman a la grafía histórica. Al contradecir el arcaico paradigma decimonónico, ${ }^{32}$ el White de Betancourt no pierde de vista la teoría tropológica, mas su enfoque radica en el esfuerzo reflexivo al interior de la propia historia como disciplina: esta autorreflexión permite vislumbrar, desvelar las distinciones (el punto ciego) y los tropos latentes a los historiadores. En resumen, las operaciones historiográficas se traducen en actos realizativos-cognitivos que, al comunicar luhmannianamente, construyen realidades. Observar dichas operaciones, la observación de segundo grado, posibilita historiarlas, describir sus modelos de explicación; lo cual nos lleva al célebre giro historiográfico. ${ }^{33}$

En definitiva, es de vital importancia considerar la pluralidad al momento de adentrarse en la lectura de este libro. Así como no hay un pasado, sino muchos en tanto las lecturas que se hagan de éstos, también hay múltiples Hayden White: no existe una esencia inmutable del historiador norteamericano, no hay tal dato o he-

31 Durán, Inventando a Hayden White, 233.

32 Durán, Inventando a Hayden White, 230. La “vieja 'filosofía sustantiva de la historia”. Ver Fernando Betancourt, "La fundamentación del saber histórico en el siglo xx: investigación social, metodología y racionalidad operativa”, Estudios de Historia Moderna y Contemporánea de México, 40 (2010): 91120.

33 Ver Alfonso Mendiola, "El giro historiográfico: la observación de observaciones del pasado", Historia y Grafia, 15 (2000), 181-208. 
cho. Desde Metahistoria (1973) hasta El pasado práctico (2014) asistimos a una muy rica y variada forma de pensamiento que padece de continuas reformulaciones, reajustes; sin perder de vista la infinidad de observaciones que podemos hacer acerca de White desde los diferentes presentes cognoscentes. En consecuencia, el lector se dará cuenta de que es inevitable sumergirse en una inmensidad de posibilidades (contingencias) a medida que incrementamos la reflexividad con la que nos acercamos al mundo... sólo así haríamos justicia a Hayden White. Más que ver el enunciado (a White), debemos ver la enunciación (las observaciones producidas acerca de él; la manera en que leemos-escribimos sus textos). Inventando a Hayden White estriba en las distintas cargas semánticas que ocho autores han asignado al autor en cuestión a través de la escritura. Qué mejor homenaje.

En esta obra no se habla de lo mismo aun cuando el tema sea Hayden
White. Se atienden las lecturas u observaciones que los ocho colaboradores de este coloquio han realizado acerca de él. Resulta muy llamativo hallarse en las últimas páginas con ocho concepciones disímiles de White; como si cada capítulo hubiera estado dedicado a un autor diferente, con ciertas aproximaciones en consonancia. Al final, uno termina obteniendo una novena observación sobre White, la propia, quizá la más valiosa, porque es el sabor que nos deja el libro: uno de matices, de pluralidad, de replanteamientos y hasta de contradicciones... al fin y al cabo, éste es nuestro White, el que hemos inventado. Siguiendo la relación dialógica entre texto y receptor de una comunicación, al final, cada lector interpelado tendrá su White propio "desde el punto de vista hermenéutico, todo texto es polisémico"; ${ }^{34}$ de cierta forma, dándole una cualidad de interminable a la obra. ${ }^{35}$ 